\title{
Comprehension of Architectural Construction through Multimedia Active Learning
}

\author{
Ángeles Mas ${ }^{1}$, Vicente Blasco ${ }^{1}$, Carlos Lerma ${ }^{1} \&$ Quiteria Angulo ${ }^{1}$ \\ ${ }^{1}$ Department of Architectural Constructions, Universitat Politècnica de València, Valencia, Spain \\ Correspondence: Carlos Lerma, Department of Architectural Constructions, Universitat Politècnica de València, \\ Cmno, Vera s/n 46022, Valencia, Spain. Tel: 34-963-879-455. E-mail: clerma@csa.upv.es
}

Received: November 14, 2012 Accepted: February 16, 2013 Online Published: March 25, 2013

doi:10.5539/hes.v3n2p1 URL: http://dx.doi.org/10.5539/hes.v3n2p1

\begin{abstract}
This study presents an investigation about the use of multimedia procedures applied to architectural construction teaching. We have applied current technological resources, aiming to rationalize and optimize the active learning process. The experience presented to students is very simple and yet very effective. It has consisted in a simulation of an actual building situation, so that they may participate more actively in their learning experience. Conclusions are extremely positive because students surprisingly involve themselves, and they are able to visualize and understand much better the reality of the construction, which increases their motivation and consequently reinforces their learning.
\end{abstract}

Keywords: multimedia, comprehension, learning, architecture

\section{Introduction}

\subsection{Communication}

According to the respected psychologist R. E. Mayer, when carrying out any explanation, it is always better that it be done with words and drawings or images, as opposed to exclusively with words (Mayer, 2001). For example, from his observations and research he deduces that students that read a text with related images placed near the corresponding words are $65 \%$ more likely to respond correctly than those students who only read the words when asked questions related to the text (Mayer, 1990).

While this is clearly nothing new in the educational field, the truth is that many education professionals feel that they find themselves faced with something totally novel. This perception lies in the wide range of possibilities offered by multimedia communication in terms of the use of greater numbers of means that have been appearing and becoming incorporated into educational tasks.

These media, analog or digital, may vary from text and images, to animation, sound, video, etc., and it is also possible to include electronic devices - along with any other media - as multimedia.

And while the term is somewhat common and natural nowadays, having become part of our daily language, the concept multimedia is as old as human communication itself. In our interactions with other individuals, we have always expressed ourselves by speaking, writing, observing our interlocutor, and gesticulating and moving our hands.

In other words, it is nothing new to note that we have always employed sound, text, sight and animation, the mechanisms characteristic of the multimedia language. The novelty perhaps lies in the fact that currently, with the use of computers, it has expanded extraordinarily.

Experience shows us - as we have been able to see -, that when we want to explain something, we can notably improve attention, comprehension and internalization by using distinct media, as the combination of some of these means make it possible for us to imitate the usual way in which we communicate as humans. That is to say, by using various senses together to get an understanding of a single object.

In the multimedia experience we find as an additional advantage what we might consider a linear presentation, in which users must visualize the contents according to a predetermined order; and the so-called "interactive multimedia", in which users have free control over the presentation of the contents, in terms of what they want to see and when they want to see it (Tabbers, Martens, Merriënboer, 2004). 
All of this provides us with extraordinary advantages and possibilities. Thanks to these current resources and technological processes, we can easily use all these media to successfully motivate our students, such that the learning of the distinct subjects that make up our course lists become something entertaining, fun and efficient.

Combining images and words greatly helps to understand any explanation, which, as R. E. Mayer demonstrates, allows students to learn more completely than with words alone (Mayer, 1997). This strongly influences their motivation. If the content is additionally presented as a game in which the student actively participates, motivation can be further stimulated.

It has been shown that the way in which an activity is presented to students' influences their inherent motivation (Ames, 1992). Students are able to focus longer on those activities which are presented to them as games, compared with those presented as just another exercise or when it is not emphasized that they will be evaluated. Nevertheless, this approach may sometimes have the opposite effect: when presented an activity in a positive way, students might be no more interested than usual, a possibility that we will have to take into account when presenting activities.

\subsection{The Learning Process}

It is often easier to blame motivational problems in the learning process on factors inherent to the students as opposed to factors related to the teacher's performance as an educator.

For this reason and to avoid committing this mistake, we must emphasize the importance of the role of the educator and the teaching strategies that facilitate the motivation of the students. Working memory is severely limited when dealing with novel information (Sweller, 2005). To this end, we must keep in mind the individual needs of each student, taking into account that, as people, they come from distinct personal backgrounds which determine the particular ways in which they find motivation.

According to experts, an educator is someone who facilitates learning. In this way, the educator's job is to provide students with the knowledge necessary to carry out the assignments once they have been given and to teach them to think, and to promote efficient ways of thinking that make it easier to maintain their interest and motivation.

It is fundamental, therefore, to consider what it is that moves students to get involved in activities and apply themselves in their performance of these activities, to understand the reasons that they may have for trying to avoid the given activities, and how different ways of thinking influence their interest, their efforts and, consequently, their learning.

All this considered, educators must be capable of adopting criteria that allow them to evaluate whether or not their performance is adequate to successfully motivate the student and facilitate the learning process, and to draw conclusions from which to adopt new and more efficient ways of performing their role as an instructor.

\section{Method}

\subsection{University Students' Motivation}

We might define motivation as the degree to which students strive to achieve academic goals that they consider to be useful and relevant. This in mind, the purpose for motivating our students consists of awakening their interests and directing their efforts towards relevant goals.

The first and fundamental question students ask themselves is, what must I achieve? or rather, the objective. The second question makes reference to the goals to be reached, meaning the gratification they will receive. The following question is, what will be the negative effects of what I'm going to achieve? Which is in essence, the supposed cost and the negative consequences that it might imply. And finally, what is to be done in order to achieve these objectives and reach these goals, while being aware of the supposed cost?

In facing these issues, educators must try to give valid and effective responses. It is necessary for them to keep in mind the following:

- It's important to clarify the learning objectives in order to facilitate the stimulation of the necessary interest and efforts. This means that before beginning any activity it is necessary to clearly indicate what it is that the students must try to learn and what it is that they must manage to understand and be able to do with the skills they acquire as a result of the proposed activities.

- Educators should have enough criteria for evaluating whether or not their performance in regards to the proposed activities will positively contribute to the stimulation of the students' interest, efforts and learning, and to knowing what goals they are expected to achieve. 
- It's necessary for educators to be familiar with the conditions of the assignments that they plan to propose so that students do not lose interest and so their effort does not wane, which would be the opposite of the desired result.

- $\quad$ It is possible for students' motivation to diminish as expectations decline, leading to a drop in effort. It is common for students to assume that they won't be able to achieve their objective even before beginning the activity, simply because they feel that they lack the knowledge and strategies necessary to carry out the activities implied in the learning process.

The conclusions reached by those who have studied and researched these issues, indicate that what often happens is that students do not demonstrate an interest or a willingness to apply themselves because they don't learn and they don't learn because they don't know how (Alonso, 2005).

It is often said that we learn from what we know. In this way, in the distinct stages of the learning experience, it is necessary to always establish connections with what we already know and, therefore, with what we have already learned. It is for this reason that if we want the learning experience to be efficient, this must be gradual, ascending little by little in the tower of learning.

University studies represent a higher degree in the learning process of individuals. The true motivation of university students begins in the moment when they recognize that every type of knowledge they acquire brings them one step closer to achieving their academic goals. This process is fundamental, due to the fact that a motivated individual will consequently demonstrate his persistence in his academic career or in some other activity throughout the process.

If one of the fundamental purposes for motivating our students is to increase their commitment and their identification with the objectives of their studies, then they will integrate more and take on more effectively their role when they believe in the importance that their formation holds for society and for the institution that educates them.

For this reason, a large part of professors apply themselves as deeply as possible to grab their students' attention and ensure their interest in real-world applications of what they learn. In this way they aim to facilitate the learning process of the students and to make sure they meet the academic goals established at the beginning of the course. Therefore, professors must encourage their students to participate and to assume certain roles within the learning method in order to give them incentives to be responsible and to set new goals.

One of the main fears of all educators is that their students lose motivation. This concern arises at all levels of the education system but is particularly troubling in the case of students in the stage prior to university. This situation becomes more serious once the students have already begun their higher education.

This problem affects not only the general courses of each academic year, but also, and often to a greater extent, the courses of an inherently applied nature, in which students are required to exhibit a greater level of participation in class.

Very often, the lack of student motivation towards the theoretical studies and in their subsequent practical application, makes it necessary for professors to make use of resources that allow them to awaken students' interest in the subject at hand.

Among these resources, it is worth noting the following:

- $\quad$ The contextualization of the contents studied in each academic unit

- $\quad$ Continuous dialogue with the students to encourage and facilitate participatory learning

- The practical application of acquired knowledge

- $\quad$ The continuity between previously acquired knowledge and new explanations

- Clear and simple explanation of the relationship between the theoretical concepts being taught and their practical application

- $\quad$ Display of the various real-world applications of the presented contents

\subsection{Learning Architectural Construction}

Architectural construction is a discipline taught in schools of architecture, and through which architecture is defined and materialized. Additionally, this subject is unique in that here we see the concurrence of other disciplines necessary for this same purpose. For this reason, one of the main concerns that educators in architectural construction face - as in any discipline of similar nature - is for the type of work they give to their 
students as part of the learning process to be as beneficial and efficient as possible.

Teaching architectural construction requires professors to take an initial theoretical approach, which students need in order to become familiar with the wide range of techniques and systems. With this theoretical basis, students acquire the skills they need to take on applied activities, which will allow them to understand the progression of the building process, the relationship between the materials involved, its spatial situation and the knowledge of the distinct professions that take part in the materialization of architecture.

Learning to build and to design what will be built implies, therefore, learning to relate parts and functions, combining, among other things, diverse materials, structural components and construction systems. Only in this way, will students of architecture be capable of comprehending construction design as the elemental backbone that sustains architectural design.

For this reason, it is crucial that we approach this process by thoroughly analyzing every detail of a construction in all its aspects, including all the materials and elements that may influence our resolution. We must also address the analysis of any architectural and structural variables that may affect the process. In this way, it is necessary to take into account that the structural details themselves constitute the study of parts and sequences, either frozen in time or already finished, of an extensive process such as the construction of a building, requiring the prior design and execution of certain supporting elements that allow others to materialize.

It is this sequential and progressive nature, both in the design stage and in the very execution of the construction that characterizes this discipline as well as architecture itself. Architectural construction as a discipline is implicated in certain continuously and rapidly evolving technological processes. For this reason, it is fundamental that this discipline at the university level be taught in such a way that deals rigorously and in depth with conceptual bases and structural principals. We must therefore take care not to reduce the learning process to a simple set of recipes, formulas and techniques for solving those structural problems, which may arise in practical application.

As in any other discipline, what is truly important is learning to think and to reason in order to achieve a solid formation, based in certain fundamental and structural principals. This is what will allow students, and future professionals in the field of architecture, to understand and develop their knowledge and techniques, which will facilitate their capacity to adapt to the future and reinvent themselves professionally.

If the professional application is to be truly efficient and productive, it is necessary for theoretical and conceptual knowledge to be properly transmitted during the university stage. This must be done not in some abstract way but rather connected with the construction reality and with the professional world. Here is where the previously mentioned multimedia applications are going to exercise a fundamental role.

\subsection{Study Design}

The study that we have conducted had two parts, a presential part in the classroom and another with student's independent work. In the first part, two videos of the construction process of a building's part were viewed. Teachers had prepared an online platform exercise to complete the students' independent work. This exercise evaluates the student's ability to assimilate and understand the knowledge imparted. It is a series of short but specific questions. In this second part, the student must study the class and the work before performing the task online.

\section{Results}

\subsection{Multimedia Approach to the Learning Process}

During the first years of their studies, architecture students become familiar with basic concepts related to construction elements and systems that commonly appear in buildings, as well as with the main characteristics of the construction materials involved. Nevertheless, students are not yet given the opportunity to take on more ambitious projects, such as stability, insulation, watertightness, safety, functionality, final appearance, feasibility of execution, etc.

In our subject, we have recently begun to deal in depth with the construction process as it relates to its materialization in architectural projects. For this purpose, we have applied a critical and rigorous teaching methodology that allows for the evaluation of distinct building situations and their alternatives aiming improving students' knowledge, so that they may be qualified for:

- Acquiring a global perspective of the relationship and compatibility between the varying construction elements involved in the design and construction of buildings.

- Establishing what best suits the application of the various construction systems and solutions, according to 
their most significant characteristics and qualities.

- Being able to evaluate, through comparative analysis, the differences in aptitude among various construction alternatives in order to resolve a problem.

Any building and all its parts are three-dimensional objects and we can observe continuity between these parts. Additionally, almost any system influences, or is influenced by other systems and elements. Nevertheless, this discipline has traditionally and conventionally been taught by generally representing construction details with the use of flat, two-dimensional planes.

However, while these two-dimensional perspectives are always very necessary when focusing on important elements and their representation in blueprints, they prove insufficient, especially at the learning phase, to understand how a structural system will perform in relation to the other elements and systems with which it is connected.

In this respect, from an educational point of view, we have always tried to supplement blueprints and two-dimensional sections with perspectives, with photography, with videos and with 2D images arranged in sequences that follow the execution of the project, since the problem arises when a system is related or connected to other elements or systems, which is always the case in architecture.

\subsection{Understanding the Process}

It is thus necessary to think, analyze and understand what happens beyond the two-dimensional plane in which we work, and therefore the third dimension becomes an unavoidable reality. It is here that we must make a greater effort, not only to represent, but also to illustrate to our students (still novices in the subject) the relevance of the third dimension and thus the many ways in which some systems determine the performance of others.

As the number of situations to be resolved may be very large and the foresight into the wide range of plausible particular cases may be very extensive, the job of educators should be to focus on preparing their students so that they themselves might be able to pose the questions-demands and look for the answers-solutions to meet the needs of three dimensions within structural coherence.

However, we are faced with another important issue. In order to correctly define and analyze structural systems, it is necessary to consider, in addition to the height, width and depth, a fourth dimension: time, the construction process itself. It is fundamental to be familiar and to control this process, the process of execution, the step by step, as it often determines the solution to a dilemma. We must, therefore, pay close attention to every moment and to every task that will ultimately play a role in the materialization of the construction.

It is here that we shall see the importance of the current opportunities offered by multimedia applications as they will allow for the fusion of distinct expressive media that aid us in our global understanding of the problems at hand.

\subsection{Images on the Blackboard and Interactive Learning}

In short, it seems clear that the typical two-dimensional constructional detail, while being common and necessary, requires the third and fourth dimension previously mentioned for the proper education of future architects.

That in mind, in our subject we have for many years provided our students with applied structural design activities on the blackboard, requiring them to participate directly, such that they become familiar with recognizing the influence that some parts of the building have or may have over a detailed construction design. With this foundation, they develop the ability to recognize, gauge and assess the group of determining factors, as well as to make decisions about the global situation.

We start with a building, described in the preliminary design or base design stage, to then develop and define its materialization. For this purpose, some students are asked to render the building in a drawing on the blackboard, from the sketch to the smallest detail.

In each applied session, some students participate with the professor to solve the presented exercises on the blackboard. In this way, the professor makes suggestions and asks questions to detect mistakes, oversights, determining factors not taken into account, etc. so that the students may understand what happens here and there, or what comes before and after. With this interactive learning method, students quickly become aware of the interrelation with other systems and the fact that the execution process is decisive and cannot be ignored.

It is important that students hear the lesson previously and grasp images, thus figures help learning. When students perform the online exercise we can provide in some cases their response through visual cues (Tabbers, 
Martens, \& Merrienboer, 2004) to obtain better results.

This way of working on the blackboard - that is, this learning method - proves to be highly effective for two reasons. Firstly, students quickly and easily comprehend what they are being taught because they can clearly visualize it. Additionally, students are motivated because they understand and comprehend more easily what is being developed. This increases their interest since they can see the immediate correspondence between what they are learning and its real-world application to architecture, so that they, hence, learn faster and more effectively.

However, this method of explaining is a conventional and traditional teaching resource that has the disadvantage of being a slow process that requires a high level of concentration, and great involvement and effort on the part of the professor. On the other hand, this method also has a main advantage: it is precisely this slow pace that allows for a deeper comprehension of the subject, so that students are made aware of the interrelation between the various systems involved in the construction, and they are thus able to successfully reason the execution process.

\subsection{New Computer Applications}

As we have previously explained, in this day in age, thanks to computer applications and resources, it is possible to improve our educational methodology, while rationalizing and optimizing the process in a much more effective way.

The use of resources provided by new educational technologies (power point 3D presentations, virtual design, virtual models, etc.) allows us to explain in stages the execution process of a given construction element in relation to the whole of the architectural problem at hand. This way, students obtain an actual modeled comprehension of the construction reality.

Even though drawing on the blackboard continues to be the most immediate educational resource, new computer applications, once they have been defined and designed, allow us to easily, quickly and precisely create video style presentations about the process of executing any construction element, effectively and efficiently introducing the fourth dimension we mentioned earlier: time and the actual sequence of the execution process. In Fig. 1 we can see the comparison between drawing on the blackboard and on the computer.
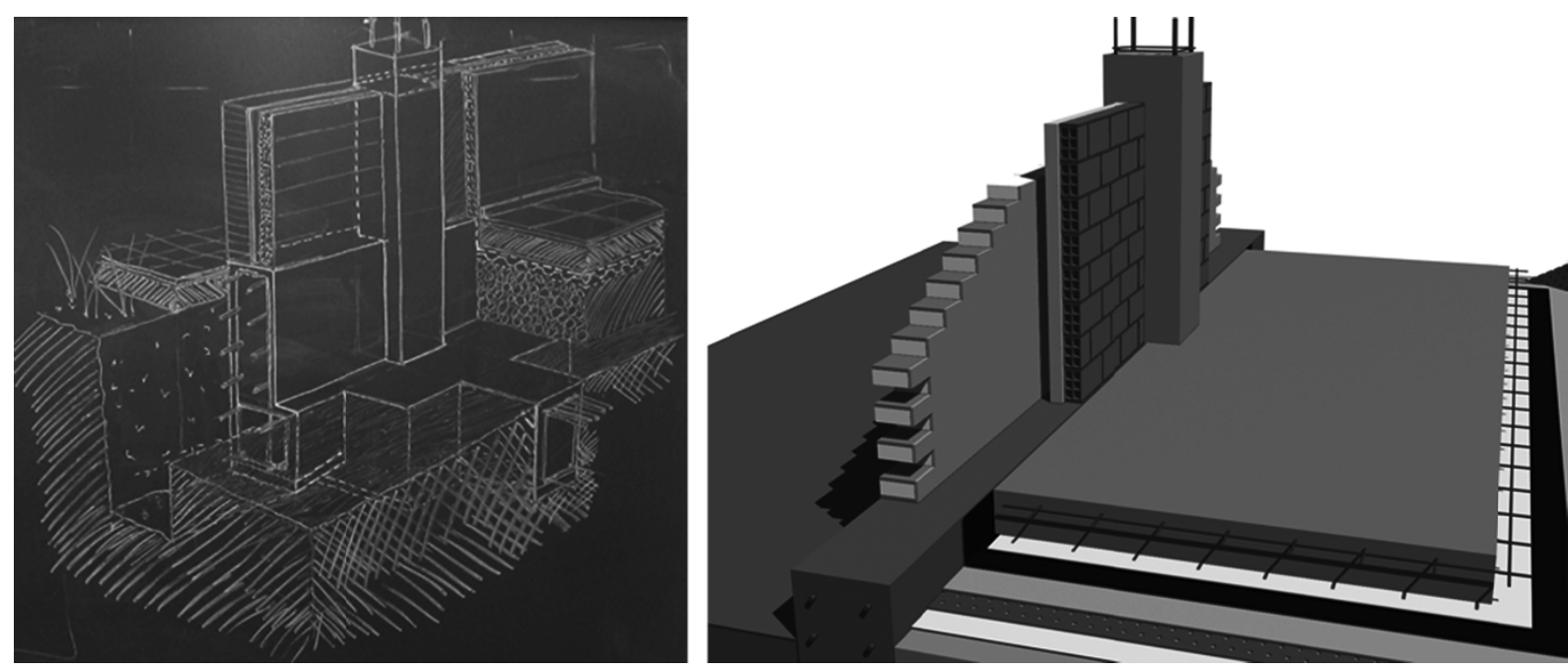

Figure 1. Comparison between drawing on the blackboard and on the computer

Just as it is necessary to follow a time sequence when building in reality, modelizations presented to students must reproduce that same process, so as to educate our students in an entertaining and graphic way, and so they become fully aware of the interrelation between the different materials involved in the execution and the construction process necessary for the ultimate materialization. In this way, they come to understand the series of layers and steps that need to be developed consecutively, as if they were dealing with a real building project.

\subsection{The Multimedia Experience}

The program Microsoft Power Point at one time facilitated the development of very detailed construction 
sections with neat, clear and precise presentations of those drawings that had previously been rendered with chalk on the blackboard. Currently, with the wide range of possibilities offered by multimedia applications (Kozma, 1994), we can fuse text, sound, graphics and video to elaborate a three-dimensional and sequential model of the construction element, thus completing the interactive process.

For the past four academic years, 2008-2009, 2009-2010, 2010-2011 and 2011-2012, we have created a multimedia experience aiming to ultimately observe the results and draw corresponding conclusions, so that the learning process may be better and more entertaining, effective and efficient for our students, thus increasing their motivation, which is, ultimately - as we have previously explained throughout this paper - what contributes to that higher level of learning we seek.

In this way, we have created educational videos, working with vector images that allow us to store and modify information like its position in the scene, its color and size, and also to modify the perspective or the picture in function with the time. We created thousands of images by taking pictures of the same model in different stages of the construction process that, put together in a sequence, take on the appearance of a video.

The three-dimensional model was produced with the program Autodesk AutoCAD 2009®, composing the picture according to diverse layers, one for each principal element (separators, footing reinforcement, tiling...). The purpose of the layer-based composition is to designate a specific "material" to each layer.

Then the AutoCAD file is exported to the program Austodesk 3D Studio Max 2009®, which allows us to illuminate the scene, to assign the materials and to visualize the model from any perspective.

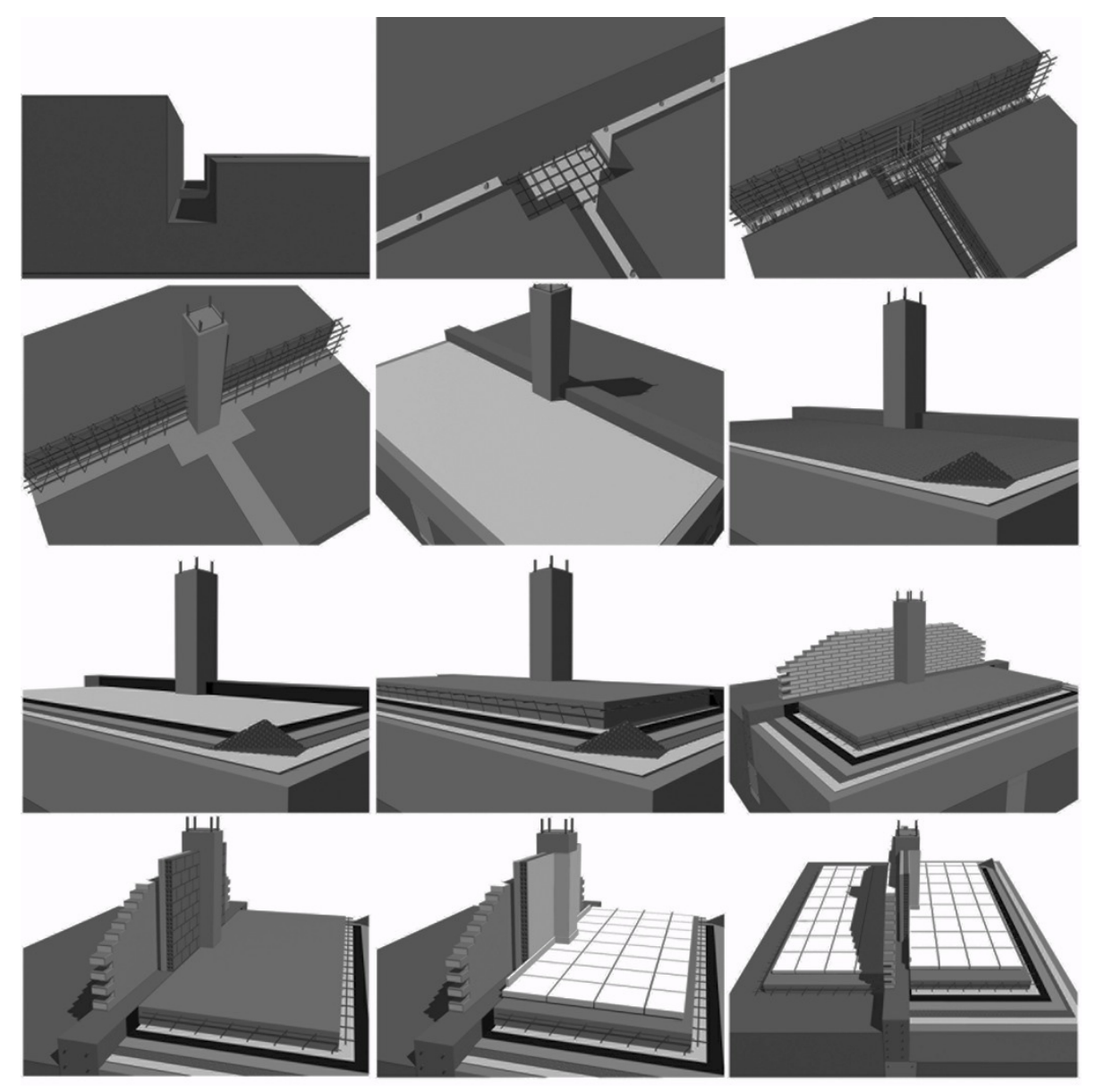

Figure 2. The execution process

Using the 3D Studio program we created two videos. The first one has a length of 6200 frames or renders, with a speed of 30 frames per second, and lasts 3 minutes and 23 seconds. It takes up $680 \mathrm{MB}$ and was created with a $800 \times 600$ pixel resolution. The second video consists of 7000 frames and, with the same speed of 30 frames per 
second, lasts 3 minutes and 57 seconds. It takes up $830 \mathrm{MB}$ with an identical resolution.

The structure of the video is as follows. The 3D model, composed of distinct construction elements, is generated according to the pertinent execution process. In other words, the different objects appear gradually in the scene from some exterior point until they settle in their designated position. The objects placed in front of the camera have been sectioned so as not to obscure the objects behind them, allowing for a better understanding, as we can see in Fig. 2.

The scene has a single static light source that completely illuminates the space. To better visualize any hidden details a back-up spotlight has been used. Finally, the titles and the watermark that appear in the video have been inserted using the program Adobe Premiere Pro 1.5®. This audio-video editing program makes it possible to add text, images and sound to the still frame and to determine the time that they appear on the screen.

The materials applied to certain objects are dynamic. This means that the materials may evolve with time. We used this characteristic so that they appear transparent for a few moments (while the objects move) and later turn opaque (once they have reached the designated position). The material was chosen such that they represent the actual object. To make it easier for students to understand and pay attention to the construction process, we decided not to use textures in the materials (images of concrete, gravel, metal...).

\subsection{Educational Use}

The experience created in both of these courses was the same and consisted of the following elements:

In one of the applied sessions of the course, an exercise that was proposed the week before is explained and performed according to the generally used method, that is, drawing the entire construction process on the blackboard while the students analyze the distinct alternatives and solutions that might be employed. In the following session, students' review what was explained in the previous session, with the prepared video projections playing an important role.

Both of the videos are explained by the professor as the images appear. As the sequence progresses the professor pauses at each image in which students are shown a new material or a new layer to be placed over a previous one. The professor continues in this way until both of the videos have ended. Once the videos have been viewed carefully, attention turns again to the projection. However, this time, it is the students who must explain what it is that will appear in each of the proceeding sequences. The goal is for all of the students to participate, which is why the activity should follow the order of students according to their position in the classroom, as if they were playing a game, making it more fun and entertaining.

We tailor material presentation to the student's learning style, as they learn more efficiently and more effectively (Carver, Howard, \& Lane, 1999).

The session ends by taking one last look and reviewing a final time, emphasizing those aspects which may have proven most difficult, or rather, those stages where the professor observed larger numbers of mistakes committed by students in their responses. Previously, the students have been advised to take good notes and pay careful attention to everything that is being done because later, using the online application "PoliformaT" they will be asked to answer some related questions about everything that was explained and developed in class, in other words, everything they have seen and heard.

This process is carried out exactly the same in each of the six different groups into which students in this course are divided. Once the process has been explained to every group, the following day, the corresponding test is posted online. To complete the test, students must open the computer program and within the short time that has been previously established, they must respond to the questions. The responses are organized, sorted and processed in order to generate corresponding graphs and evaluate the experience and its results.

\section{Discussion}

Our course is divided into six groups (A, B, C, D, E, F), represented in Fig. 3 on the x-axis. In this graph, all of the results are shown in percentages. The percentages of students that completed the exercise in each group have been represented. This figure shows the time that students took in the exercise.

A very large percentage of students that attend class have completed this activity, which could only be solved online. The index of class attendance and that of participation in the activity show the involvement of each group. We can see that group B is the most involved and that group E is one of the afternoon groups with low student attendance. The average grade in all of the groups is higher than $85 \%$, which leads us to understand that the results of the experience are very good, given that, in addition, the lowest grades are outliers and do not fall below $45 \%$ which tells us that a large majority of students who complete the exercises pass them. 
Fig. 4 shows the responses sent in by students from the time they were allowed to complete the exercise until the submission period ended for that purpose. In light gray we see the submitted responses for this activity that increase with time. In dark gray we have the submissions that were made each day.

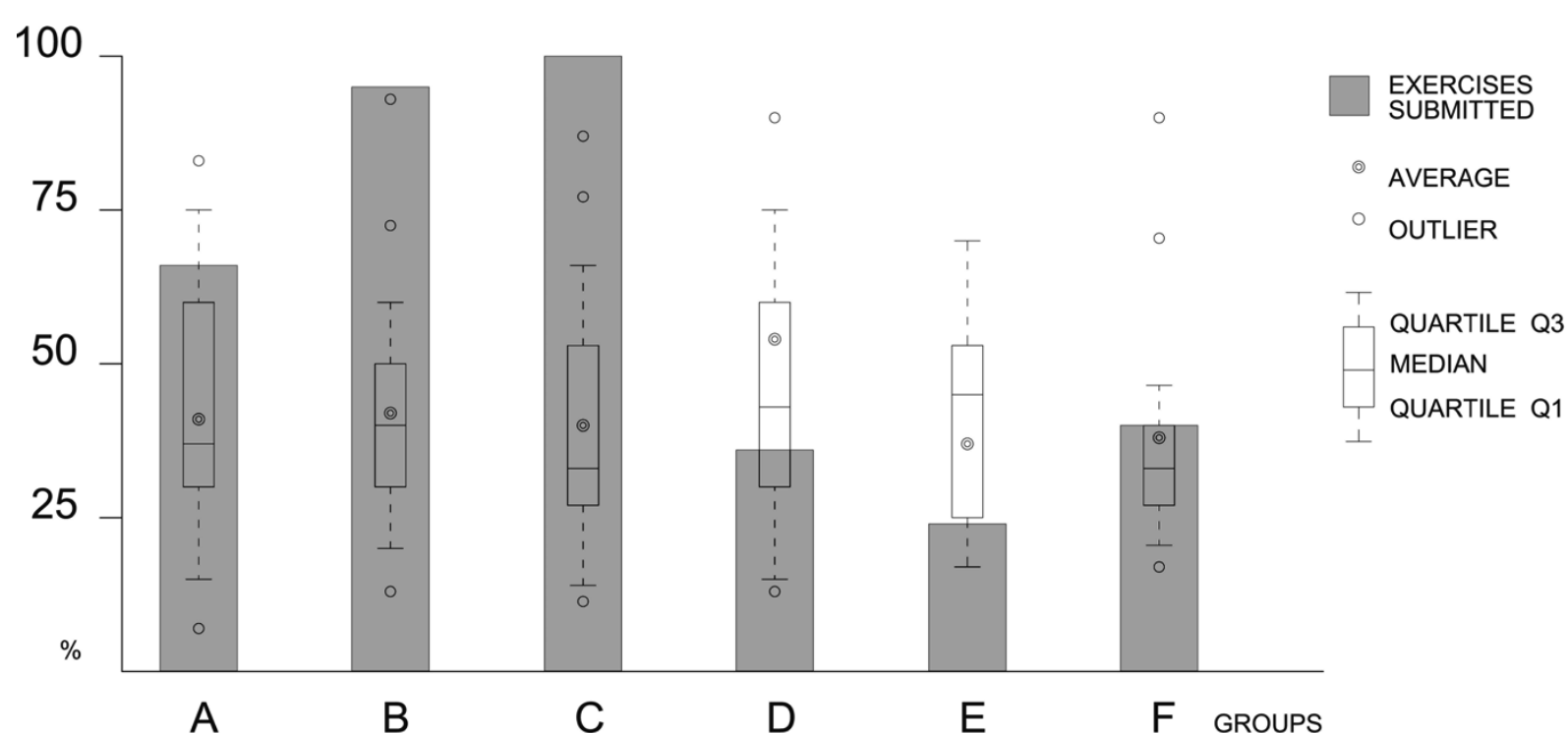

Figure 3. Time to perform the exercise

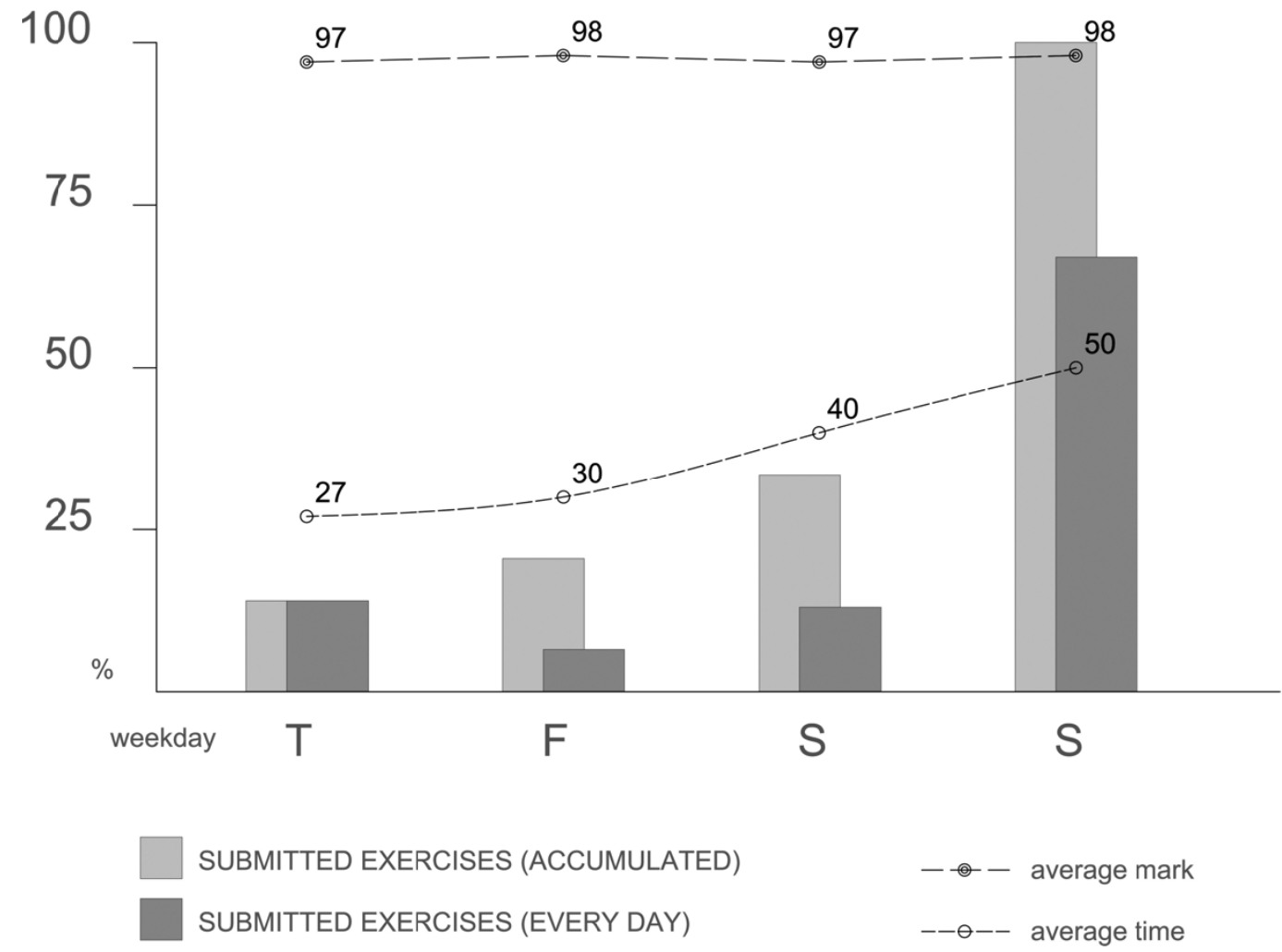

Figure 4. Participation and results

This becomes evident in the trend line. Clearly those students more interested in the exercise started working on it within its first days online. However, the majority of students answered the questions the day before or even the same day that the submission period closed. It's clear that the average grade for the exercises decreases as a function of time along the linear equation (trend line). 
The majority of exercises were solved the day before the closing of the submission period, although the best results were obtained by students that completed the exercise in its first days online.

The presented exercise consisted of ten questions. Fig. 5 analyzes the number of correct answers submitted by students in every group. The average value of correct responses per question, is indicated, along with the range of values. The groups that obtained the highest and lowest grades are noted at their respective values. The average value of correct responses for all questions is $88 \%$.

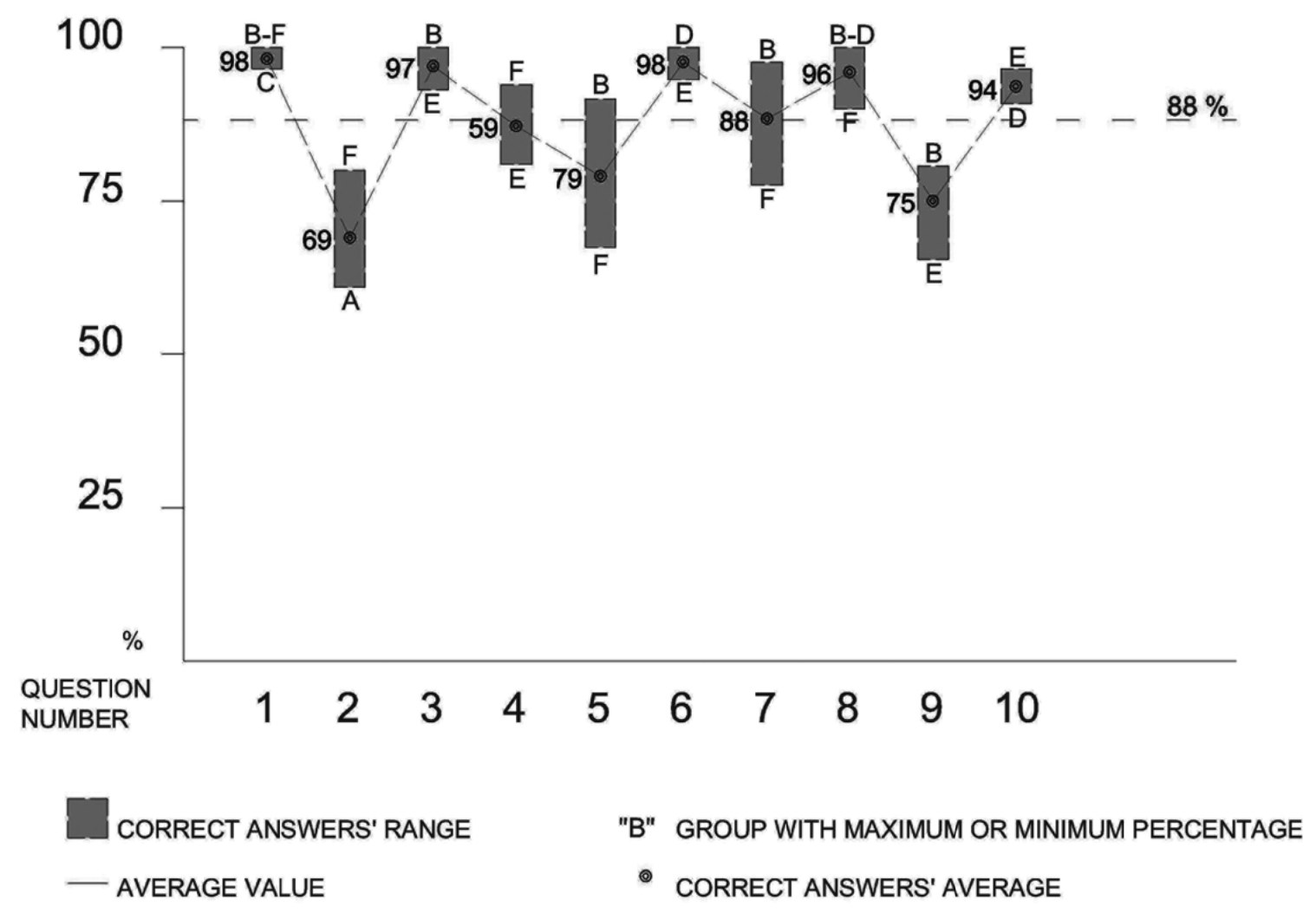

Figure 5. True answers for each question

\section{Conclusion}

As we have been developing throughout this paper, one of the main goals of this experience was to evaluate the application of new educational methods intended to increase motivation and, therefore, to improve the level of learning in our students. We have successfully shown that, thanks to the use of new technologies, the use of new multimedia applications might allow us to make our applied sessions - which until now had been carried out according to traditional methods of explanation, drawing on the blackboard -, easier to understand. The ultimate objective is for students to find themselves more motivated and, consequently, to learn in an entertaining, captivating way, almost without realizing, almost without being aware of their learning process, which are the indicators of a truly effective educational experience.

Our goal here is to be able to observe that educational methodologies can be improved through the incorporation of multimedia into our teaching methods. Where we had previously used exclusively drawings accompanied by oral explanation - as we have always done in our case -, we can now draw the conclusion that if we add animation to visualize the process in a pertinent order, attention remarkably improves, comprehension increases in a general basis and, most importantly, motivation surprisingly rises.

With this experience, consisting of the application of computers to the active learning of architectural construction, students are able to successfully understand the construction process in its entirety, acquiring the fundamental skills for its subsequent development, such as the spatial comprehension of anything that may occur when facing a building problem and finding solutions. 
This particular way of facing problems generates a special motivation in students, which serves as a starting point so that education in the classroom may come to acquire a professional approach to the reality of forms, materials, dimensions, techniques and textures in the actual time sequence involved in any building process.

\section{References}

Alonso, J. (2005). Motivar en la escuela, motivar en la familia. Madrid: Ediciones Morata, S. L.

Ames, C. (1992). Classroom: Goals, structures and student motivation. Journal of Educational Psychology, 84(3), 261-271. http://dx.doi.org/10.1037/0022-0663.84.3.261

Carver, C. A., Howard, R. A., \& Lane, W. D. (1999). Enhancing student learning through hypermedia courseware and incorporation of student learning styles. IEEE Transactions on Education, 42(1), 33-38. http://dx.doi.org/10.1109/13.746332

Kozma, R. (1994). Will media influence learning? Reframing the debate. Educational Technology Research and Development, 42, 1-19. http://dx.doi.org/10.1007/BF02299087

Mayer, R. E. (1997). Multimedia learning: Are we asking the right questions? Educational Psychologist, 32, 1-19. http://dx.doi.org/10.1207/s15326985ep3201_1

Mayer, R. E. (2001). Multimedia learning. New York: Cambridge University Press. http://dx.doi.org/10.1017/CBO9781139164603

Mayer, R. E., \& Gallini, J. K. (1990). When is an illustration worth ten thousand words? Journal of Educational Psychology, 82, 715-726. http://dx.doi.org/10.1037//0022-0663.82.4.715

Sweller, J. (2005). An integrated model of text and picture comprehension. In R. E. Mayer (Ed.), The Cambridge Handbook of Multimedia Learning. Universtity of California.

Tabbers, H. K., Martens, R. L., \& Merrienboer, J. J. G. (2004). Multimedia instructions and cognitive load theory: Effects of modality and cueing. British Journal of Educational Psychology, 74, 71-81. http://dx.doi.org/10.1348/000709904322848824

Tabbers, H. K., Martens, R. L., \& Van Merriënboer, J. J. G. (2004). Multimedia instructions and cognitive load theory: Effects of modality and cueing. British Journal of Educational Psychology, 74(1), 71-81. http://dx.doi.org/10.1348/000709904322848824 